\title{
Animal Welfare and Organic Aquaculture in Open Systems
}

\author{
Stephanie Yue Cottee $\cdot$ Paul Petersan
}

Published online: 14 July 2009

(C) Springer Science+Business Media B.V. 2009

\section{Erratum to: J Agric Environ Ethics DOI 10.1007/s10806-009-9169-2}

The last paragraph of the section "Genetic Effects" should not be indented with the preceding quoted text. The corrected formatting is reprinted below including the leading paragraph.

These impacts necessitate an evaluation of the long-term survival of some wild salmon populations (Fleming et al. 2000). In their paper on fitness reduction and extinction, McGinnity and co-authors (2003) summarized:

Irrespective of the exact extent of fitness reduction, the fact that farm escapes are repetitive, often resulting in annual intrusions in some rivers, means that such reductions in fitness are cumulative, which could potentially lead to an extinction vortex in endangered populations.

Eliminating escapes is the best way to decrease harmful interactions between escapees and their wild counterparts (Bridger and Garber 2002). The only way to effectively eliminate escapes in organic systems, however, is to prohibit use of net pens.

Bridger, C. H., \& Garber, A. (2002). Aquaculture escapement, implications, and mitigation: The salmonid case study. In B. A. Costa-Pierce (Ed.), Ecological

The online version of the original article can be found under doi:10.1007/s10806-009-9169-2.

\section{S. Y. Cottee}

Department of Animal and Poultry Science, University of Guelph, Guelph, ON N1G 2W1, Canada

P. Petersan $(\bowtie)$

The Humane Society of the United States, 2100 L St. NW, Washington, DC 20037, USA

e-mail: papetersan@humanesociety.org

URL: http://www.hsus.org 
aquaculture: The evolution of the blue revolution (pp. 77-102). Malden, MA: Blackwell Science.

Fleming, I. A., Hindar, K., Mjølnerød, I. B., Jonsson, B., Balstad, T., \& Lamberg, A. (2000). Lifetime success and interactions of farm salmon invading a native population. Proceedings of the Royal Society B: Biological Sciences, 267(1452), 1517-1523.

McGinnity, P., Prodöhl, P., Ferguson, A., Hynes, R., Maoiléidigh, N. O., Baker, N., et al. (2003). Fitness reduction and potential extinction of wild populations of Atlantic salmon, Salmo salar, as a result of interactions with escaped farm salmon. Proceedings of the Royal Society B: Biological Sciences, 270(1532), 2443-2450. 